\title{
New cleroid beetles from the Middle-Late Jurassic of China
}

Jiří Kolibáč and Diying Huang

Acta Palaeontologica Polonica 64 (1), 2019: 143-155 doi:https://doi.org/10.4202/app.00550.2018

Four specimens of fossil beetles recorded from the Middle and Late Jurassic boundary beds of Inner Mongolia, China are assigned to the melyrid lineage of Cleroidea. Three of them are described as Sinomelyris praedecessor gen. et sp. nov. and constitute the earliest known representatives of the family Melyridae. The new species habitually resembles some extant beetles of the subfamily Melyrinae but it is distinctly smaller and possesses four elytral carinae, the pronotum without a pair of the dorsolateral carinae, and the tarsal claw simple. The fourth specimen Juraniscus majeri gen. et sp. nov., is classified as Cleroidea incertae sedis. The new species has the symmetrical antennomeres including three terminal ones, the tarsomeres $1-4$ with the lobes, the tarsal claw simple, and the aedeagus with the separated parameres. It is considered to be a member of the melyrid lineage and its relations to the relevant families Mauroniscidae, Rhadalidae, Dasytidae, and Malachiidae are discussed. A complete list of fossil species in the melyrid lineage described to date is provided.

Key words: Coleoptera, Cleroidea, Melyridae, Mesozoic, Inner Mongolia, Daohugou.

Jiří Kolibáč [jkolibac@mzm.cz], Moravian Museum, Department of

Entomology, Brno, Czech Republic. Diying Huang [dyhuang@nigpas.ac.cn], State Key Laboratory of Palaeobiology and Stratigraphy, Nanjing Institute of Geology and Palaeontology, Chinese Academy of Sciences, Nanjing, China.

This is an open-access article distributed under the terms of the Creative Commons Attribution License (for details please see creativecommons.org), which permits unrestricted use, distribution, and reproduction in any medium, provided the original author and source are credited. 
Full text $(1,170.7 \mathrm{kB})$ 
